УДК 69. 03.338. 5

ЭКОНОМИЧЕСКИЙ ЭФФЕКТ АВТОМАТИЗАЦИИ

ОРГАНИЗАЦИИ СТРОИТЕЛЬСТВА ИНФРАСТРУКТУРНЫХ ОБЪЕКТОВ НЕФТЕДОБЫВАЮЩЕЙ ОТРАСЛИ

\title{
ECONOMIC EFFECT OF ORGANIZATION AUTOMATION IN THE OIL-PRODUCING INDUSTRY INFRASTRUCTURAL OBJECTS CONSTRUCTION
}

Е.В. Кузнецова, О.В. Смородова, М.К. Кабиров, Р.Р. Алмакаев

Уфимский государственный нефтяной технический университет, г. Уфа, Российская Федерация

Elena V. Kuznetsova, Olga V. Smorodova, Maksud K. Kabirov, Ruslan R. Almakaev

Ufa State Petroleum Technological University, Ufa, Russian Federation e-mail: olga_smorodova@mail.ru

Аннотация. Труднодоступность месторождений нефти и газа Российской Федерации, связанная с их специфическим географическим расположением, осложняет и удорожает их эксплуатацию. Высокоэффективные методы организации строительства инфраструктурных объектов, в частности нефтепромысловых дорог, позволяют достичь существенных экономических эффектов для предприятий - заказчиков и подрядных строительно-монтажных организаций. Сетевые модели организации производства строительномонтажных работ являются классически рекомендуемыми к использованию в процессе организации проектирования и непосредственного производства строительно-монтажных работ по сооружению инфраструктурных объектов. Существует два метода расчета 
сетевых моделей - секторный и табличный. И хотя секторный метод, по мнению авторов, является более наглядным, однако он практически не применяется в связи со сложностью расчета. Табличный метод расчета может вызывать еще большие затруднения в связи с некоторой оторванностью таблицы расчета от самой сетевой модели. Реализация обоих методов расчета требует достаточно высокой квалификации персонала проектной организации, длительного времени, может вызывать ошибки в процессе разработки и расчета сетевой модели в связи с большими объемами сетей и разрозненностью исходной информации. Авторами данной статьи была разработана оптимизирующая система «Argan», целью разработки которой явилось упрощение работы с сетевыми моделями, сокращение сроков производства проектных и в последующем строительно-монтажных работ, массовое внедрение сетевых моделей в процессы проектирования, реализации и управления производством строительно-монтажных работ. Внедрение отдельных информационных модулей позволяет облегчить и ускорить сбор исходной информации для расчета проекта организации работ, повысить производительность труда в проектных организациях, в случае оптимизации сроков производства работ относительно нормативных получить экономические эффекты и заказчику и подрядчику, величина которых зависит от объема инвестиций.

Abstract. The inaccessibility of oil and gas fields of the Russian Federation, associated with their specific geographical location, complicates and increases the cost of their exploitation. Highly effective methods of organizing the construction of infrastructure facilities, in particular oil fields, allow achieving significant economic effects for enterprises - customers and contractors of construction and installation organizations. Network models for the organization of construction and installation works are classically recommended for use in the process of organizing the design and direct production of construction and installation works for the construction of infrastructure facilities. There are two methods for calculating network models - sector and tabular. And although the 
sectoral method, according to the authors, is more obvious, however, it is practically not used due to the complexity of the calculation. The tabular calculation method can cause even greater difficulties due to some isolation of the calculation table from the network model itself. The implementation of both calculation methods requires a sufficiently high qualification of design organization personnel, for a long time, it can cause errors in the process of developing and calculating a network model due to the large volumes of networks and the fragmentation of the initial information. The authors of this article developed a computer program «Argan», the development of which was to simplify working with network models, reducing the time for design and subsequent construction and installation works, mass introduction of network models in the design, implementation and management of construction and installation works. The introduction of separate information modules makes it easier and faster to collect baseline information for calculating the project for organizing work, to increase labor productivity in design organizations, and if the timing of work is optimized relative to the normative ones, the economic effects will be possible for both the customer and the contractor, the magnitude of which depends on the volume of investments.

Ключевые слова: строительство; экономический эффект; сетевой график; сокращение сроков; моделирование

Key words: construction; economic effect; network diagram; reduction of terms; modeling

Запасы нефти и газа в Российской Федерации - одни из самых крупных в мире [1], однако большинство из них находятся в труднодоступных и малонаселенных территориях Сибири и Урала. Значительную часть этих территорий составляют тундровые леса, зоны вечной мерзлоты, а также торфяные грунты, слагающие болотистую местность. Это значительно осложняет и удорожает обслуживание месторождений, которое 
невозможно осуществить без доставки на него рабочего персонала, оборудования, различных строительных материалов и техники. Данную проблему помогают решить нефтепромысловые автомобильные дороги.

Строительство автомобильной дороги технологически включает в себя множество различных взаимосвязанных и взаимозависимых процессов, как правило, отличных друг от друга по продолжительности выполнения [2-4]. Без должной организации последовательности работ и правильного распределения ресурсов происходят задержки и паузы в выполнении одних процессов, в ожидании завершения других процессов, непосредственно связанных с ними [5]. Кроме этого, может снизиться качество работ, выполняемых в условиях ограниченного времени [6, 7]. Стоит отметить также, что возведение автомобильной дороги требует значительного количества машин и механизмов, финансовых ресурсов, затрат труда, строительных материалов [8, 9]. Несоблюдение графиков производства работ приводит к росту затрат на выполнение строительномонтажных работ и, следовательно, к убыткам строительной организации или заказчика [10].

Из вышесказанного следует вывод, что без должной организации строительного процесса падает производительность труда, качество производства работ, увеличиваются стоимость и сроки выполнения работ, дата окончания строительства становится непредсказуемой.

Данная проблема особенно актуальна в современности. Затраты на обустройство нефтегазового месторождения неизбежно ложатся на плечи потребителя в результате передачи расходов на обустройство месторождения через себестоимость добычи нефти и газа [11]. Чем лучше организован процесс строительства автомобильной дороги, тем ниже расходы на объект в целом [12-14], выше производительность труда строительной организации, и, в случае сокращения сроков производства строительно-монтажных работ против нормативных, возможно достижение эффекта от досрочного ввода в эксплуатацию основного 
объекта нефтедобывающей отрасли $[15,16]$. Добиться этого позволяют современные методы организации проектирования и строительного производства $[17,18]$, в числе которых имеются сетевые модели производства работ и методы их решения $[19,20]$.

На основе теории о сетевых моделях производства работ и табличного метода их решения авторами создана система «Argan». При ее разработке преследовалась иель создания единого комплекса из нескольких модулей, позволяющих максимально упростить и автоматизировать процесс расчетов временных параметров сетевых моделей производства при выполнении строительных и ремонтных работ в дорожной отрасли. При помощи системы также можно выявлять критический путь при производстве строительно-монтажных работ, и, в случае необходимости, оптимизировать сетевую модель. Кроме этого, система позволяет установить календарные сроки выполнения работ.

Как показывает опыт, в большинстве своем организация строительного производства на предприятиях дорожно-строительной отрасли заключается в построении линейных календарных графиков (рисунок 1), не способных, в отличие от сетевых моделей (рисунок 2), на основе которых выполняется программный расчет, показать полную взаимосвязь между работами, точные сроки начала и окончания производства работ, а также величины резервов времени $[21,22]$.

В случае же, если проектная организация, а в последующем и аппарат управления дорожно-строительной организации используют именно сетевые модели, расчет их выполняется вручную, частично либо полностью. Это может вызывать затруднения и требовать значительного количества времени на выполнение проектных работ на стадии разработки проекта организации строительства и проекта производства работ в последующем, в случае необходимости, при оптимизации сетевой модели.

Блок-схема разработанного авторами комплекса «Argan» представлена на рисунке 3. 


\begin{tabular}{|c|c|c|c|c|c|c|c|c|c|c|c|c|c|c|}
\hline \multirow[b]{2}{*}{$\begin{array}{l}\dot{\delta} \\
\dot{z}\end{array}$} & \multirow{2}{*}{$\begin{array}{l}\text { Начменование } \\
\text { операцич,марка } \\
\text { машины }\end{array}$} & \multirow{2}{*}{$\begin{array}{l}\text { 0бъём } \\
\text { радот }\end{array}$} & \multirow{2}{*}{$\begin{array}{l}\text { Производ. } \\
\text { в смену }\end{array}$} & \multirow{2}{*}{ 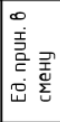 } & \multirow{2}{*}{ 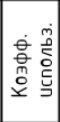 } & \multirow[b]{2}{*}{ Состав звена } & \multirow{2}{*}{ 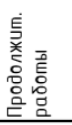 } & \multicolumn{2}{|c|}{ День 1} & \multicolumn{2}{|c|}{ День 2} & \multirow{2}{*}{\begin{tabular}{|c|} 
День 3 \\
Смена 1 \\
\end{tabular}} & \multicolumn{2}{|c|}{ День 10} \\
\hline & & & & & & & & Смена 1 & Смена 2 & Смена 1 & Смена 2 & & Смена 1 & Смена 2 \\
\hline 1 & $\begin{array}{l}\text { Срезка р. с. бульдозером } \\
\text { ДЗ-171.4 }\end{array}$ & $2319 \mathrm{M}^{2}$ & $2887 \mathrm{M}^{2}$ & 1 & 0,8 & Машинист 6 разр. - 1 & 0,8 & $\longrightarrow$ & & & & & & \\
\hline 2 & 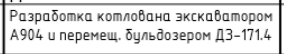 & $280,1 \mathrm{~m}^{3}$ & $563,9 \mathrm{M}^{3}$ & $1+1$ & 0,5 & 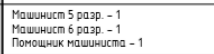 & 0,5 & & -1 & & & & & \\
\hline 3 & $\begin{array}{l}\text { Упл. осн. котп. вибропп. } \\
\text { BPR } 40 / 45 \text { D }\end{array}$ & $165 \mathrm{~m}^{2}$ & $316,4 \mathrm{M}^{2}$ & 1 & 0,46 & $\begin{array}{l}\text { Дорожный рабоччӣ } 3 \\
\text { разр. - } 1\end{array}$ & 0,46 & & $\longmapsto$ & & & & & \\
\hline 4 & $\begin{array}{l}\text { Tранспортитровка } \\
\text { ПГС - КАМАЗ-551111 }\end{array}$ & \multirow{3}{*}{$133,8 \mathrm{~m}^{3}$} & $33,6 \mathrm{~m}^{3}$ & 4 & 1 & Водитель 5 разр. - 5 & 1 & & $\vdash$ & $\longrightarrow$ & & & & \\
\hline 5 & \begin{tabular}{|l|} 
РазраВниВанше ПГС \\
бульдозером ДЗ-171.4
\end{tabular} & & $721,8 \mathrm{M}^{3}$ & 1 & 0,19 & Машинист 6 разр. - 1 & 0,19 & & $\vdash$ & -1 & & & & \\
\hline 6 & 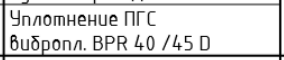 & & $94,96 \mathrm{M}^{3}$ & 2 & 0,47 & $\begin{array}{l}\text { Дорожный рабоччй } 3 \\
\text { разр. - } 2\end{array}$ & 0,47 & & $\vdash$ & -1 & & & & \\
\hline 7 & $\begin{array}{l}\text { Доста6ка дорожных ж/ठ } \\
\text { nлUт - КАМАЗ-65117 }\end{array}$ & \multirow{2}{*}{$109,2 \mathrm{~m}$} & $33,44 \mathrm{~m}$ & 4 & 0,82 & Водитель 5 разр. - 4 & 0,82 & & $\vdash$ & -1 & & & & \\
\hline 8 & $\begin{array}{l}\text { Paзгр. U yKn. пnum } \\
\text { краном KC-55732 } \\
\end{array}$ & & $272,96 \mathrm{~m}$ & 1 & 0,4 & 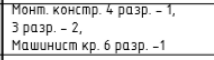 & 0,4 & & $\vdash$ & $\square$ & & & & \\
\hline 9 & $\begin{array}{l}\text { Tрансп цем. раст. } \\
\text { a6mодетоносм. СБ-92В-2 }\end{array}$ & \multirow{2}{*}{$8,56 \mathrm{~m}^{3}$} & $11,28 \mathrm{~m}^{3}$ & 1 & 0,76 & Машинист 6 разр. - 1 & 0,76 & & & $\mapsto$ & $\longrightarrow$ & & & \\
\hline 10 & \begin{tabular}{|l|} 
Устрройство верхн. осн. Чз \\
цементного раств. Вручннуюо \\
\end{tabular} & & $25 \mathrm{M}^{3}$ & 2 & 0,17 & \begin{tabular}{|l} 
Moнm. констр. 4 разр. - 2, \\
2 pasp. - 2
\end{tabular} & 0,17 & & & $\mapsto$ & +1 & & & \\
\hline 11 & 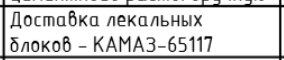 & & $35,6 \mathrm{~m}$ & 3 & 0,69 & Водитель 5 разр. - 3 & 0,69 & & & & $\longmapsto$ & -1 & & \\
\hline 12 & $\begin{array}{l}\text { Pазгрузка лекальных } \\
\text { блоков краном КС-55732 } \\
\end{array}$ & & $145,28 \mathrm{~m}$ & 1 & 0,51 & 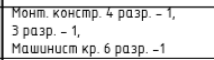 & 0,51 & & & & & -1 & & \\
\hline 13 & \begin{tabular}{|l} 
Доставка порm. ст., опк. \\
кр. ч огол. - KAMA3-65117
\end{tabular} & $60 \mathrm{~m}$ & $35,6 \mathrm{~m}$ & 2 & 0,96 & Водитель 5 разр. - 2 & 0,96 & & & & & $\longmapsto$ & $H$ & \\
\hline
\end{tabular}

Рисунок 1. Фрагмент линейного календарного графика выполнения работ

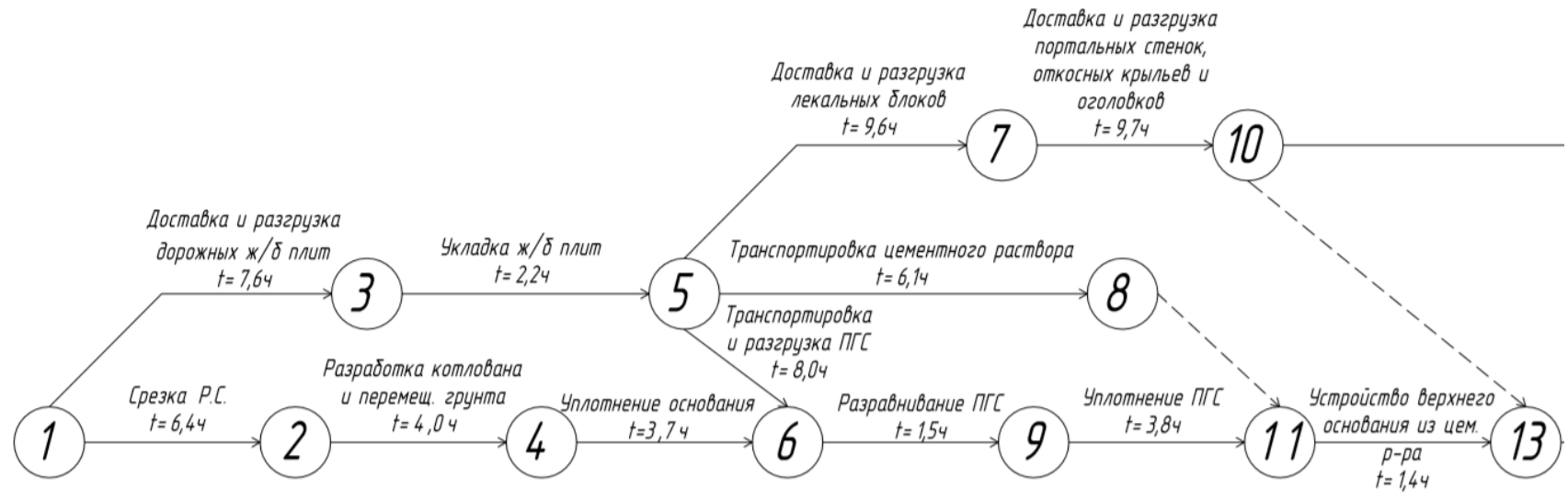

Рисунок 2. Фрагмент сетевой модели выполнения работ

Упростить и ускорить расчет продолжительности выполнения работ для сетевой модели призван модуль «Карточка-определитель» (рисунок 4), данные для которого определяются на основе сметной части проекта. Гибкие настройки путем изменения количества и продолжительности смен и коэффициента перевыполнения норм выработки позволяют аппарату управления адаптировать отдельно взятые работы или проект в целом под текущие планы организаций заказчика и подрядчика. 


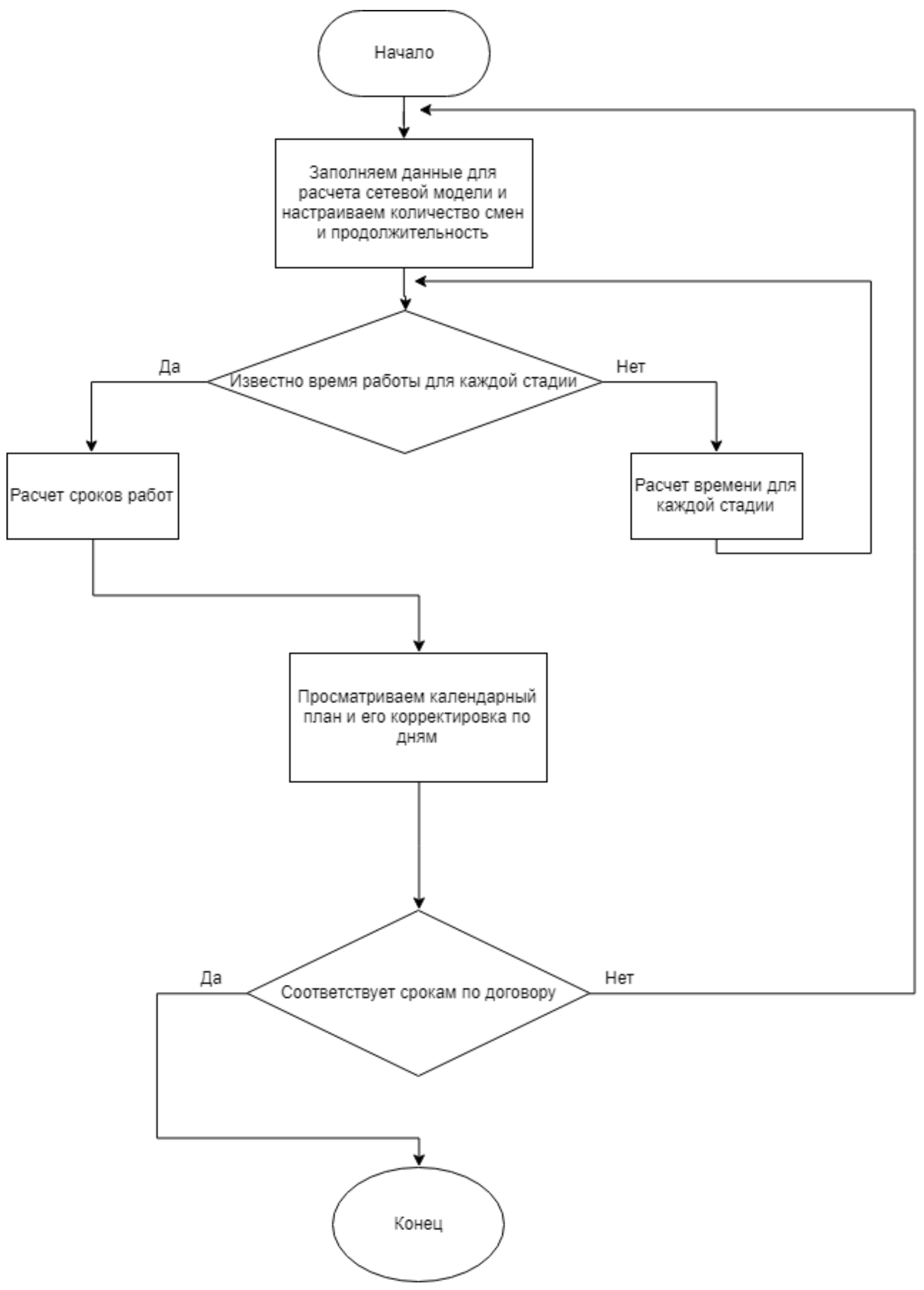

Рисунок 3. Блок-схема модуля оптимизации работ «Argan» 


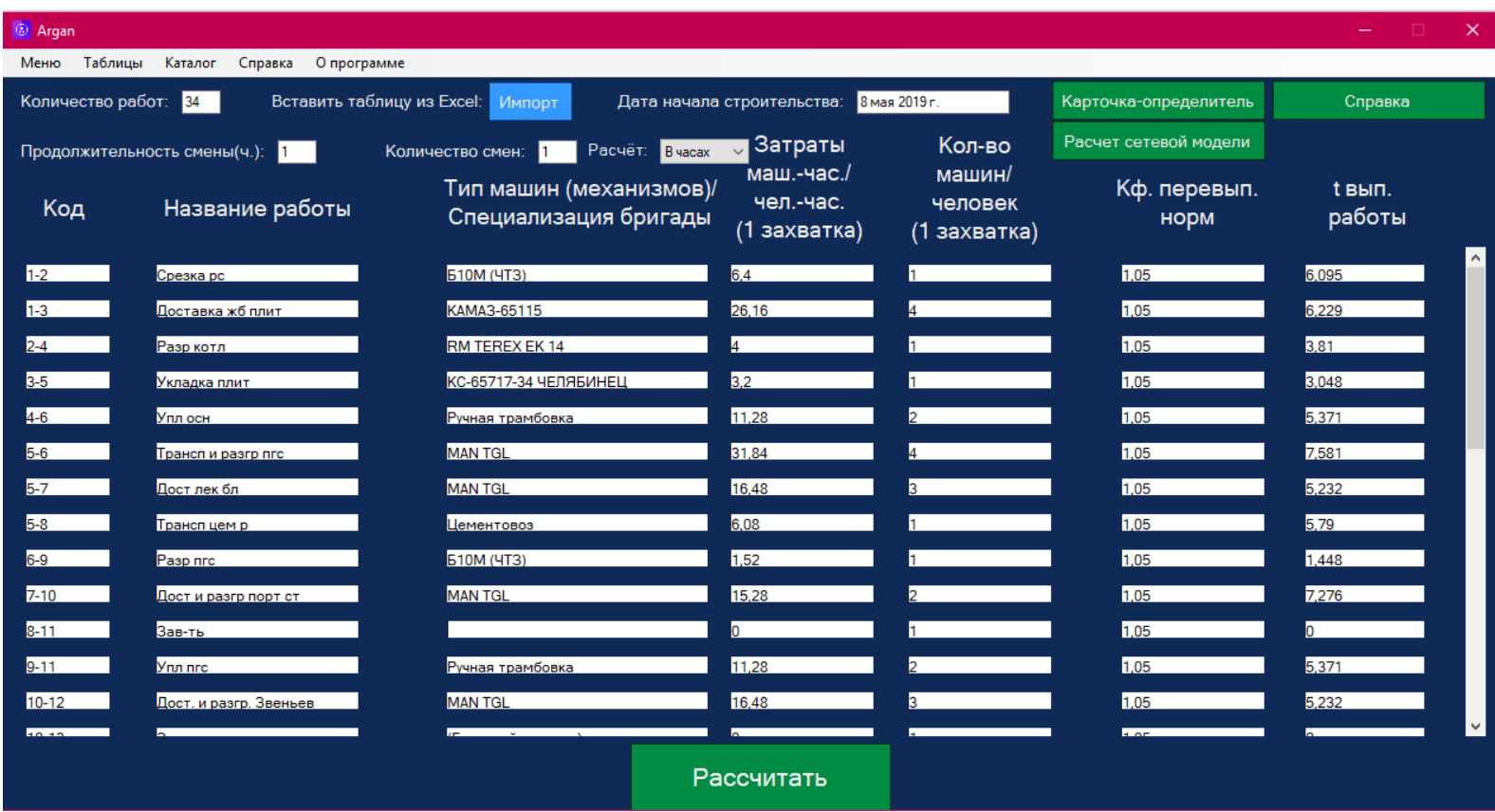

Рисунок 4. Карточка-определитель

Расчет сетевой модели в целом табличным методом вручную занимает достаточно длительное время, требует значительной концентрации внимания и отсутствия ошибок в расчетах. Программа «Argan» автоматически импортирует данные из модуля «Карточка-определитель» в карточку «Расчет сетевой модели» (рисунок 5). В результате расчета удается выделить наиболее важные работы, от своевременного выполнения которых зависит успешное завершение строительства в намеченные сроки. Наиболее важные с точки зрения управления работы составляют так называемый «критический путь». Работы критического пути требуют от управленца наибольшего внимания, так как резервы времени по данному типу работ отсутствуют.

После расчета сетевой модели возможна привязка проекта к календарным датам.

Это очень важная функция, которая позволяет проектировщикам или производителям работ точно определять сроки начала и окончания производства отдельных видов работ и проекта в целом и соблюдать тем самым договорные обязательства подрядной организации. 


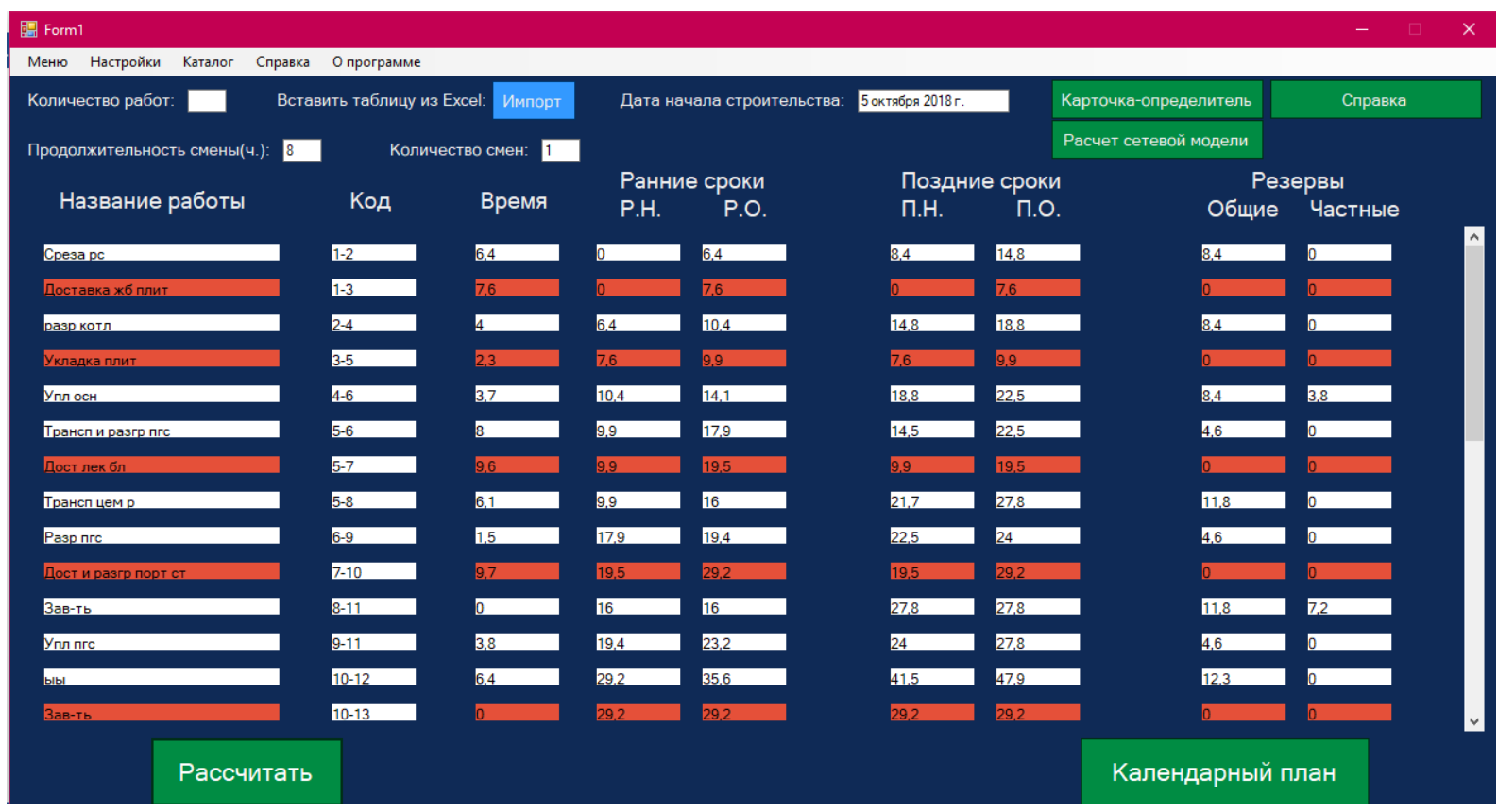

Рисунок 5. Результаты расчета сетевой модели

Модуль «Календарный план» (рисунок 6) заменяет собой рабочий календарь строительной организации и дает возможность определять календарные даты всех производимых видов работ и проекта в целом с учетом выходных и рабочих дней с возможностью самостоятельного их назначения.

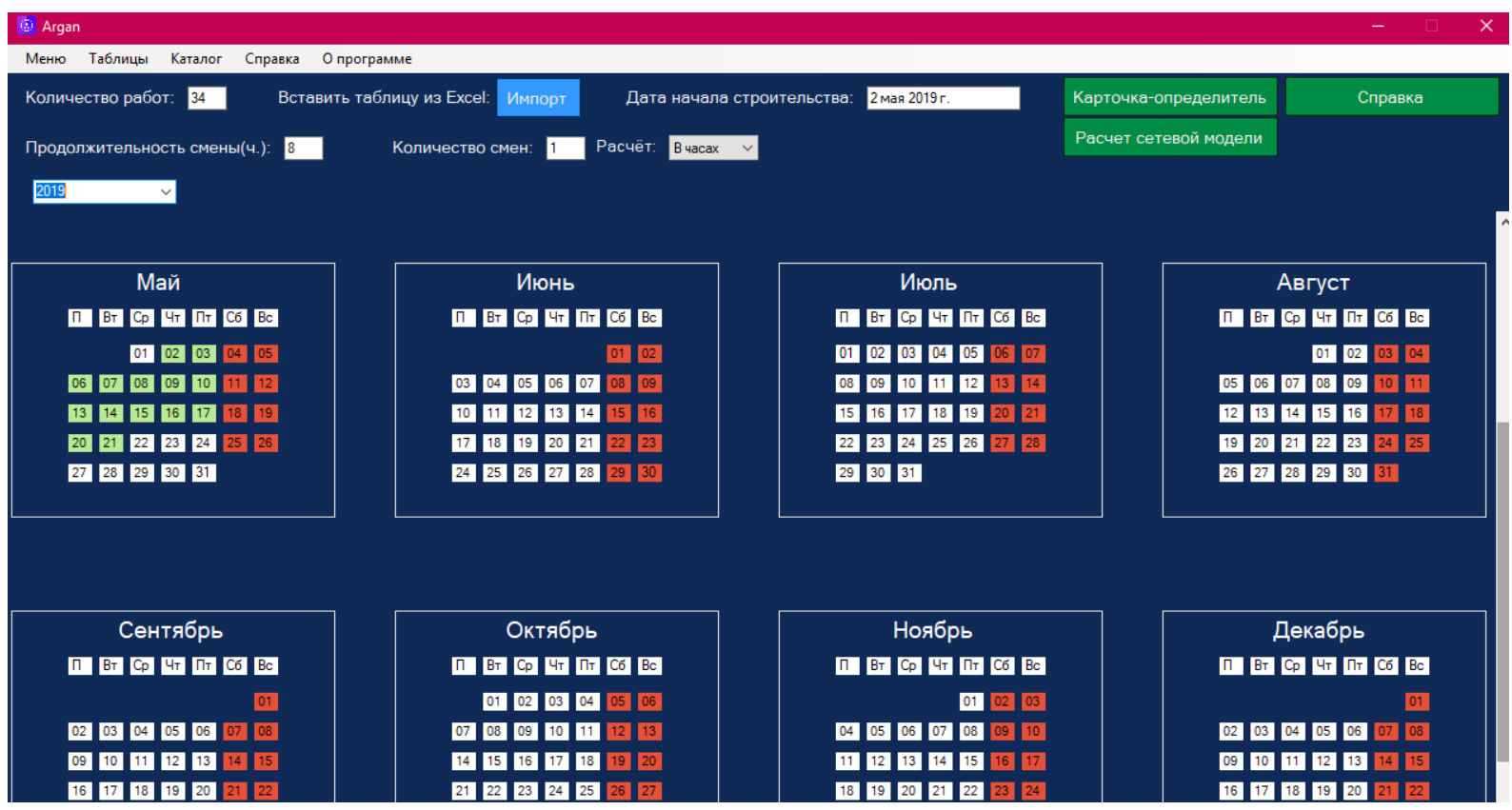

Рисунок 6. Календарный план с периодом производства работ (зеленые ячейки) и выходными днями (красные ячейки) 
Продолжительность и количество смен при выполнении работ также учитываются.

Особым преимуществом программного комплекса, в отличие от ручного или частично автоматизированного расчета, является функция создания отчета в электронном виде формата «Microsoft Excel» как по результатам расчета модуля «Карточка-определитель» (рисунок 7), так и модуля «Расчет сетевой модели» (рисунок 8).

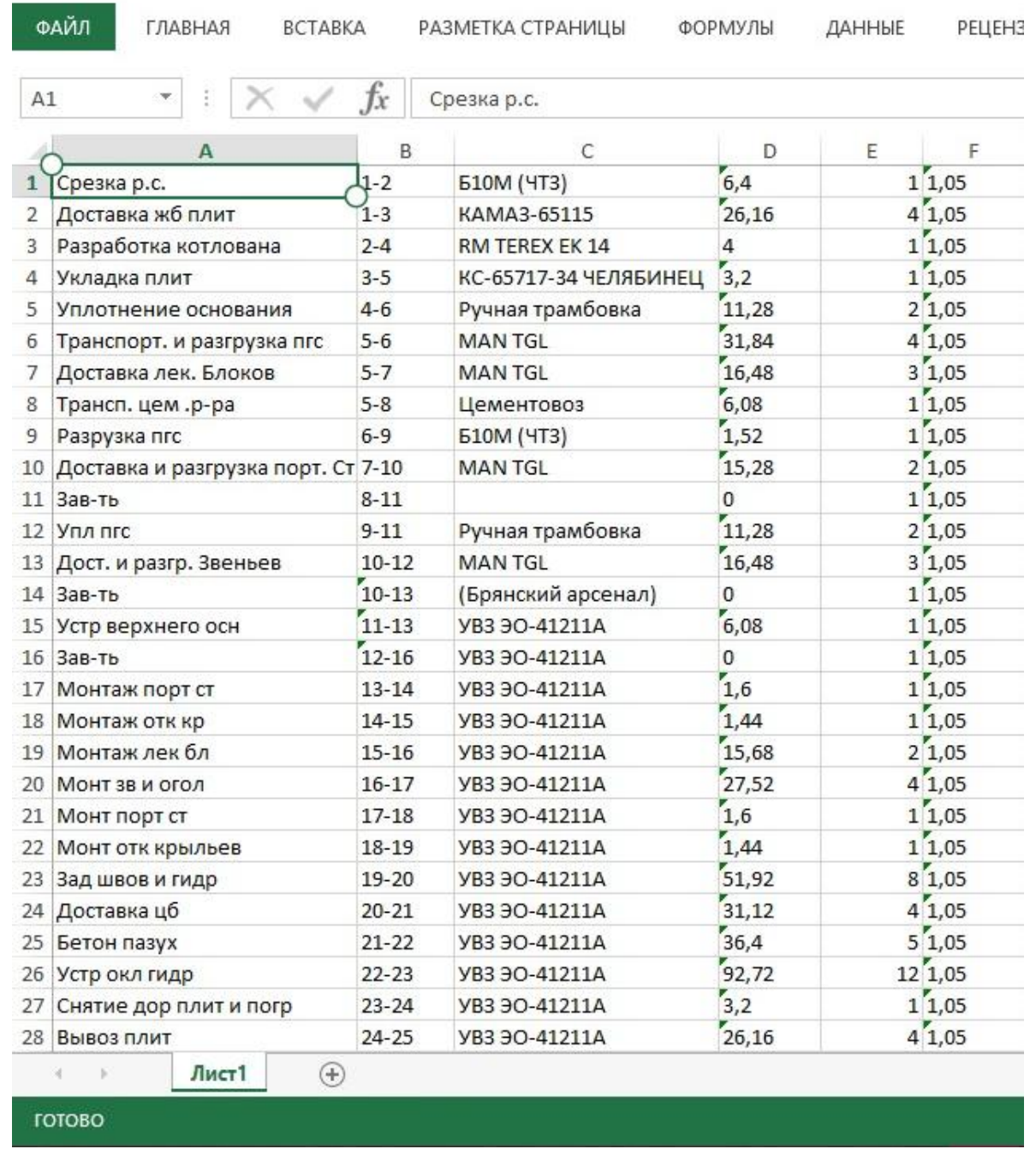

Рисунок 7. Отчет модуля «Карточка-определитель» в электронном виде

Функция импортирования данных из файла формата «Microsoft Excel» позволяет оперативно реагировать на изменения в плане работы предприятия, что значительно повышает производительность аппарата управления, благодаря отсутствию необходимости ручного перерасчета 
времени выполнения работ, сетевой модели и календарного графика. Создаваемый и импортируемый отчет идентичны и обратно совместимы между собой.

\begin{tabular}{|c|c|c|c|c|c|c|c|c|c|c|}
\hline \multicolumn{2}{|c|}{ ФАЙЛ } & ГЛАВНАЯ & \multicolumn{2}{|c|}{ BCTABKA } & \multicolumn{2}{|c|}{ РАЗМЕТКА СТРАНИЦЫ } & ФОРМУлЫ & \multicolumn{2}{|c|}{ ДАННЫЕ } & \multirow[t]{2}{*}{ PELEI } \\
\hline A1 & & $\rightarrow \quad \vdots$ & $x \vee$ & $f_{x}$ & Название & & & & & \\
\hline$\Delta$ & A & B & C & D & E & $\mathrm{F}$ & G & H & 1 & \\
\hline 1 & Название & код & Время & P.H. & P.O. & п.н. & п.о. & общие & Частныє & \\
\hline 2 & Среза рс & $1-2$ & 6,4 & & 06,4 & 8,4 & 14,8 & 8,4 & & 0 \\
\hline 3 & Доставка & $1-3$ & 7,6 & & 07,6 & & 07,6 & 0 & 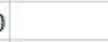 & 0 \\
\hline 4 & разр котл & $2-4$ & & 6,4 & 10,4 & 14,8 & 18,8 & 8,4 & & 0 \\
\hline 5 & Укладка п & $-3-5$ & 2,3 & 7,6 & 9,9 & 7,6 & 9,9 & 0 & o & 0 \\
\hline 6 & Упл осн & $4-6$ & 3,7 & 10,4 & 14,1 & 18,8 & 22,5 & 8,4 & 3,8 & \\
\hline 7 & Трансп и। & 15-6 & & 9,9 & 17,9 & 14,5 & 22,5 & 4,6 & & 0 \\
\hline 8 & Дост лек। & $15-7$ & 9,6 & 9,9 & 19,5 & 9,9 & 19,5 & 0 & 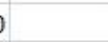 & 0 \\
\hline 9 & Трансп це & $=5-8$ & 6,1 & 9,9 & & 621,7 & 27,8 & 11,8 & & 0 \\
\hline 10 & Разр пгс & $6-9$ & 1,5 & 17,9 & 19,4 & 22,5 & & 4,6 & & 0 \\
\hline 11 & Дост и ра: & $7-10$ & 9,7 & 19,5 & 29,2 & 19,5 & 29,2 & 0 & 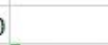 & 0 \\
\hline 12 & Зав-ть & $8-11$ & ( & & 16 & 627,8 & 27,8 & 11,8 & 7,2 & \\
\hline 13 & Упл пгс & $9-11$ & 3,8 & 19,4 & 23,2 & & 2427,8 & 4,6 & & 0 \\
\hline 14 & ыы & $10-12$ & 6,4 & 29,2 & 35,6 & 41,5 & 47,9 & 12,3 & & 0 \\
\hline 15 & Зав-ть & $10-13$ & & 29,2 & 29,2 & 29,2 & 29,2 & 0 & & 0 \\
\hline 16 & Устр верх & $11-13$ & 1,4 & 23,2 & 24,6 & 27,8 & 29,2 & 4,6 & 4,6 & \\
\hline 17 & Зав-ть & $12-16$ & & 35,6 & 35,6 & 47,9 & 47,9 & 12,3 & 12,3 & \\
\hline 18 & Монтаж п & $13-14$ & 1,6 & 29,2 & 30,8 & 29,2 & 30,8 & 0 & 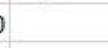 & 0 \\
\hline 19 & Монтаж о & $14-15$ & 1,4 & 30,8 & 32,2 & 30,8 & 32,2 & 0 & 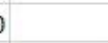 & 0 \\
\hline 20 & Монтажл & $15-16$ & 15,7 & 32,2 & 47,9 & 32,2 & 47,9 & 0 & D & 0 \\
\hline 21 & Монт зв и & $16-17$ & 27,5 & 47,9 & 75,4 & 47,9 & 75,4 & 0 & 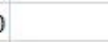 & 0 \\
\hline 22 & Монт пор & $17-18$ & 1,6 & 75,4 & & $77^{\prime} 75,4$ & 77 & 0 & ) & 0 \\
\hline 23 & Монт отк & $18-19$ & 1,4 & & 7778,4 & & $77^{\prime} 78,4$ & 0 & 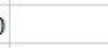 & 0 \\
\hline 24 & Зад швов & $19-20$ & 25,9 & 78,4 & 104,3 & 78,4 & 104,3 & 0 & 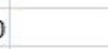 & 0 \\
\hline 25 & Доставка & $20-21$ & 7,8 & 104,3 & 112,1 & 104,3 & 112,1 & 0 & 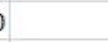 & 0 \\
\hline 26 & Бетон паз & $21-22$ & 4,6 & 112,1 & 116,7 & 112,1 & 116,7 & 0 & 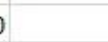 & 0 \\
\hline 27 & Устр окл г & $22-23$ & 23,4 & 116,7 & 140,1 & 116,7 & 140,1 & 0 & 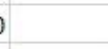 & 0 \\
\hline 28 & Снятие дс & c $23-24$ & 3,2 & 140,1 & 143,3 & 140,1 & 143,3 & 0 & 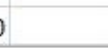 & 0 \\
\hline & 4 & Лист1 & ๑ & & & & & & & \\
\hline
\end{tabular}

Рисунок 8. Отчет модуля «Расчет сетевой модели» в электронном виде

В программном комплексе имеются вспомогательные модули, призванные оказать помощь еще на стадии формирования проекта организации строительства.

Модуль «Каталог», представленный на рисунке 9, содержит сведения о самых распространенных высокоэффективных видах и типах дорожностроительных машин и механизмов, с их изображением и наиболее важными характеристиками, способными оказать влияние на технологию производства работ и производительность работы бригад. 
Сведения о наиболее рациональном составе и квалификации рабочего звена или бригады при выполнении отдельных видов работ и операций по возведению земляного полотна или дорожной одежды можно получить из модуля «Типовые бригады рабочих отрядов в дорожной отрасли» (рисунок 10).

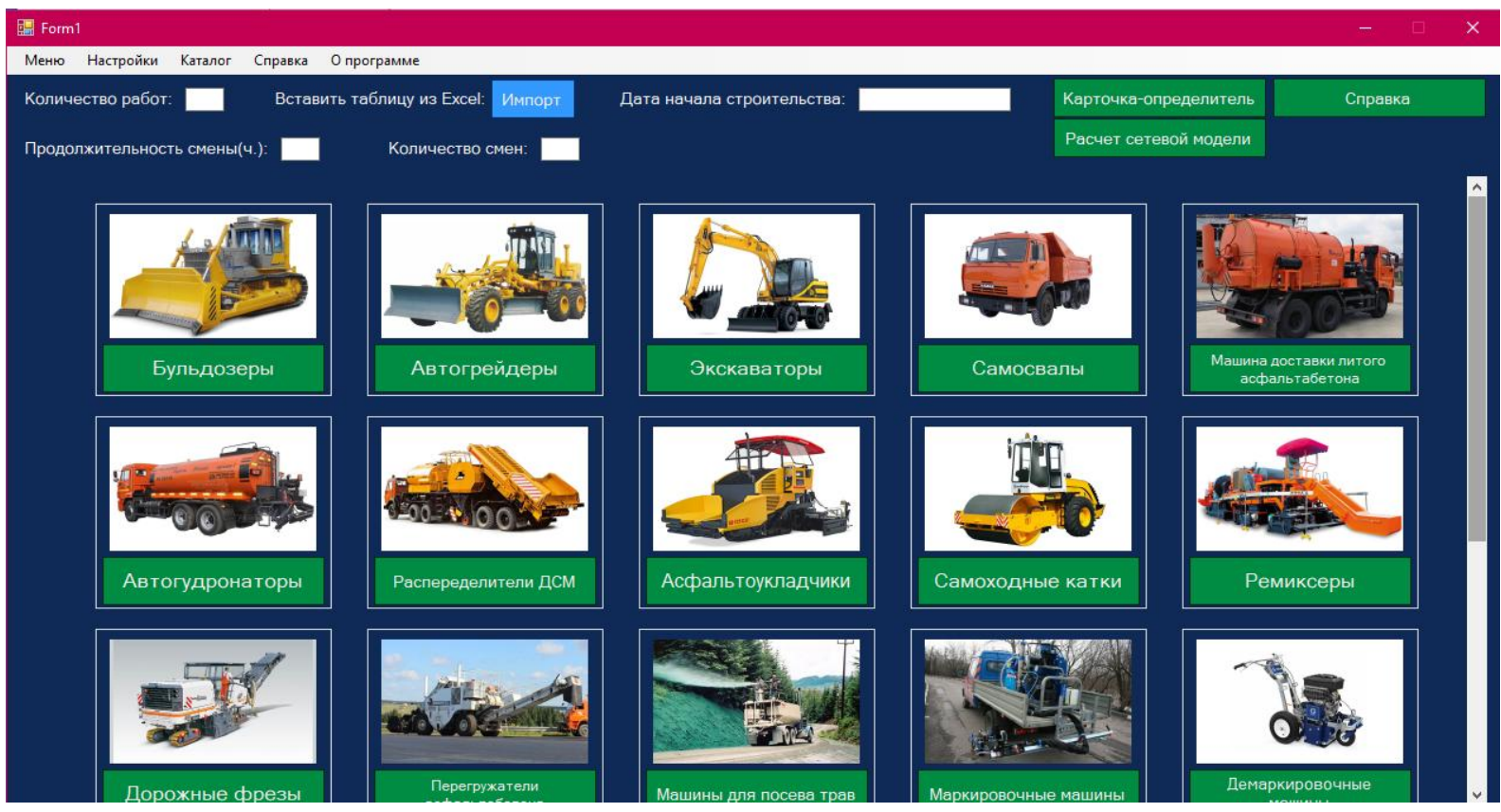

Рисунок 9. Модуль «Каталог»

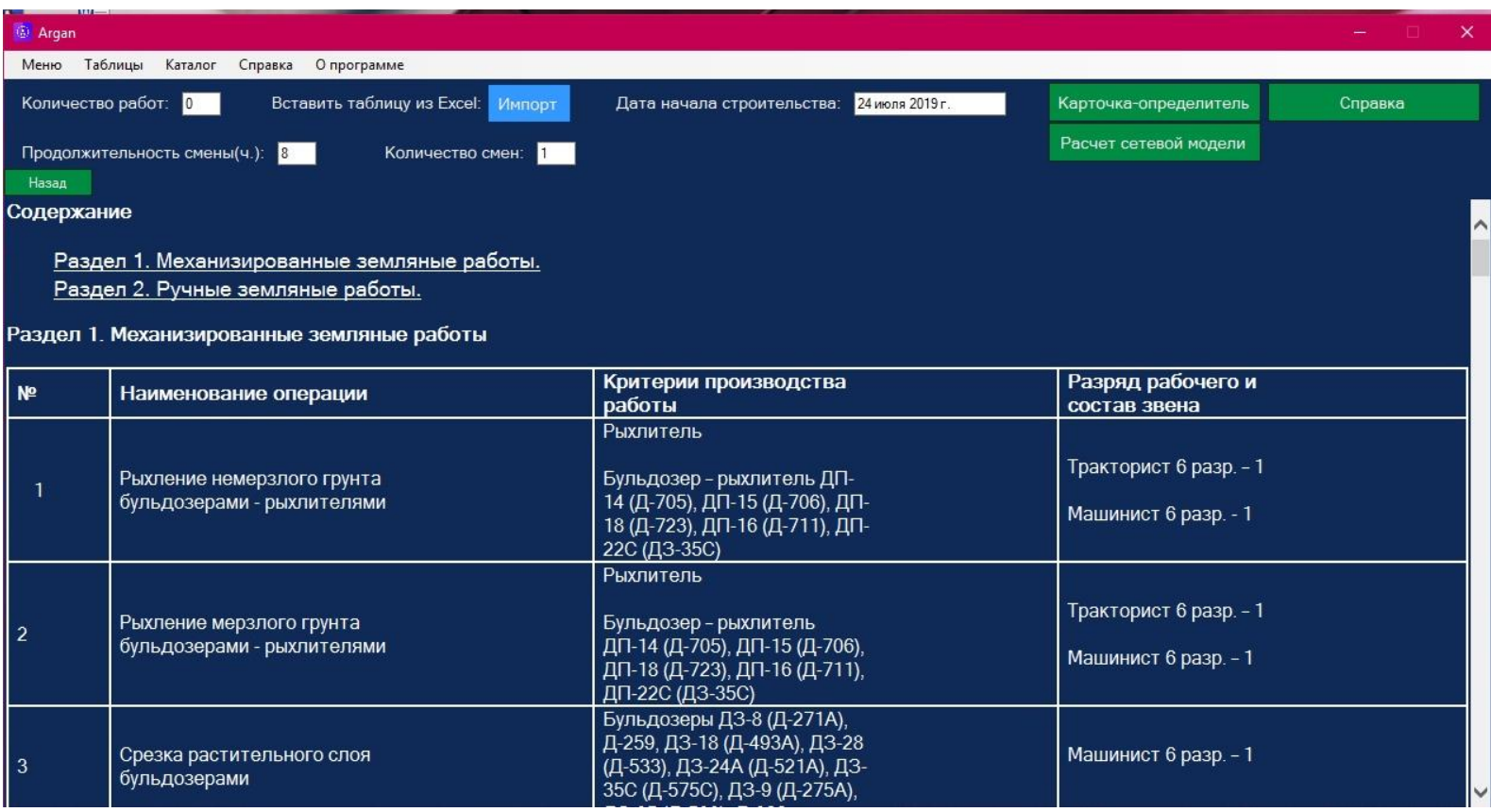

Рисунок 10. Модуль «Типовые бригады рабочих отрядов в дорожной отрасли» 
Для пользователей, незнакомых с правилами формирования сетевых моделей, заложена справочная информация, в том числе теория по составлению сетевых моделей и расшифровка терминов.

Эффект от использования данного комплекса высок, зависит от множества факторов и не может быть однозначно определен для всех случаев использования.

В общем случае, эффект от досрочного ввода объекта в эксплуатацию за счет сокращения продолжительности производства проектных и строительно-монтажных работ по сооружению автомобильной дороги выражается формулой, имеющей вид для предприятия-заказчика объекта [23]:

$$
Э_{\text {зак }}=\mathrm{E}_{\mathrm{H}} \times \Phi \times\left(\mathrm{T}_{\mathrm{H}}-\mathrm{T}_{\phi}\right),
$$

где $\mathrm{E}_{\text {н }}-$ нормативный коэффициент сравнительной экономической эффективности капитальных вложений;

$\Phi$ - стоимость досрочно вводимых производственных фондов, руб.;

$\mathrm{T}_{\mathrm{H}}, \mathrm{T}_{\phi}-$ соответственно нормативный (планируемый) и фактический сроки строительства.

Данный эффект заключается для заказчика в полученной прибыли от выпуска и реализации продукции за период между нормативным и фактическим сроками ввода объекта в эксплуатацию.

Для подрядной дорожно-строительной организации внутриотраслевой экономический эффект от досрочной сдачи объекта в эксплуатацию определяется следующим образом [11]:

$$
Э_{\text {подр }}=\mathrm{УПЧ}_{\text {нр }} \times\left(1-\mathrm{T}_{\phi} / \mathrm{T}_{\mathrm{H}}\right) \text {, }
$$

где УПЧ монтажной организации по вводимому объекту.

Данный эффект заключается в снижении себестоимости производимых строительно-монтажных работ на сумму затрат, величина которых находится в зависимости от сроков производства 
строительно-монтажных работ [24]. Данные формулы применяются для укрупненных расчетов.

В качестве примера расчета представим материалы по расчету планового внутриотраслевого эффекта от сокращения срока производства работ по возведению межплощадочной автомобильной дороги IV-в категории от автомобильной дороги куст № 54 - куст № 56 к кусту скважин № 777 Лемпинской площади Салымского месторождения Нефтеюганского района Ханты-мансийского автономного округа.

Сметная стоимость объекта с учетом проектных решений по строительству объекта на слабом основании, сложенном болотным торфом, а также искусственных сооружений, в значительном количестве имеющихся на всем протяжении проектируемой автомобильной дороги, и перспективной интенсивности и состава движения составила 21 209,580 тыс. руб. за 1 км.

Таким образом, по всему объекту строительства общая сметная стоимость составляет 390383,549 тыс. руб. При сокращении сроков производства работ на 10 дней при помощи использовании сетевого моделирования внутриотраслевой экономический эффект строительной организащии по укрупненным расчетам определяется в размере 7424,653 тыс. руб. Фактические эффекты от оптимизации процесса производства работ с сокращением продолжительности строительства определяются прямым счетом на основе бухгалтерской документации и чаще всего превышают расчетные по укрупненным показателям.

Экономический эффект основного нефтедобывающего объекта от досрочного ввода автомобильной дороги определяется мощностью основного предприятия и уровнем рентабельности предприятия нефтедобычи. 


\section{Выводы}

1. Проблема своевременности выполнения проектных и строительномонтажных работ при сооружении инфраструктурных объектов нефтедобывающей промышленности остра и приводит к снижению эффективности деятельности основного производства нефтедобывающей отрасли.

2. Авторами разработан моделирующий комплекс «Argan», позволяющий автоматизировать расчет организации строительного производства сооружения инфраструктурных объектов, добиваясь соблюдения договорных сроков производства работ.

3. Использование моделирующего комплекса «Argan» способно значительно повысить производительность труда в проектных организациях, аппаратах управления дорожно-строительных организаций, производственных отделах, а также увеличить прибыль подрядных организаций и предприятий-заказчиков за счет сокращения сроков производства строительно- монтажных работ.

\section{Список используемых источников}

1. Васильева Ю.П., Хисамутдинов И.А. Экономический рост: эффективность и ресурсная обеспеченность // Электронный научный журнал «Нефтегазовое дело». 2014. № 3. С. 342-358. URL: http://ogbus.ru/files/ogbus/issues/3_2014/ogbus_3_2014_p342358_VasilevaJP_ru.pdf (дата обращения: 04.08.2019).

2. Прокопьев А.П., Иванчура В.И., Емельянов Р.Т., Пальчиков П.А. Реализация концепции автоматизации и интеллектуализации управления дорожно-строительными процессами // Вестник МГСУ. 2018. Т. 13. № 1 (112). C. 61-70. DOI: 10.22227/1997-0935.2018.1.61-70.

3. Schtzbach A.M. The Crack and Seat Method of Pavement Rehabilitation // Public Works. 1989. No. 12. P. 52-55. 
4. Le joint actif // Revue Generale des Routes et des Aerodromes. 1990. No. 677. P. 49-51.

5. Прокопьев А.П., Иванчура В.И., Климов А.С., Емельянов Р.Т. Концепция комплексной автоматизации управления процессами строительства асфальтобетонных дорожных покрытий // Строительные и дорожные машины. 2012. № 8. С. 36-42.

6. Кузнецова Е.В., Шаймарданова А.А., Болгова А.С. Концептуальные основы инжиниринга качества // Матер. IV Bcepocc. заоч. науч.-практ. интернет-конф. «Современные тенденции в экономике и финансах». Уфа: УГНТУ, 2014. С. 109-111.

7. Колбасин А.М. Алгоритм формирования методологии управления качеством инновационных проектов в сфере дорожного строительства // Транспортное дело России. 2009. № 12S. С. 73-74.

8. Bokovikova T.N., Shperber D.R., Shperber E.R., Volkova S.S. Application of Oil-Slimes in Road Base and Surface Construction // Электронный научный журнал «Нефтегазовое дело». 2011. № 2. С. 316320.

URL: http://ogbus.ru/files/ogbus/eng/authors/Bokovikova/Bokovikova_1e.pdf (дата обращения: 04.08.2019).

9. Алферов В.И., Баркалов С.А., Курочка П.Н. Управление проектами в дорожном строительстве. Воронеж: Воронежский государственный архитектурно-строительный университет, 2009. 432 с.

10. Баркалов С.А. Теория и практика календарного планирования в строительстве. Воронеж: ВГАСА, 1999. 216 с.

11. Маслова О.П., Савкин С.О. Цели и задачи инвестиционной деятельности предприятий нефтегазовой отрасли // Электронный научный журнал «Нефтегазовое дело». 2017. № 5. С. 227-250. URL: http://ogbus.ru/ files/ogbus/issues/5_2017/ogbus_5_2017_p227-250_MaslovaOP_ru_en.pdf (дата обращения: 04.08.2019). 
12. Белобородова Н.А. Совершенствование управления развитием города в нефтегазовом регионе России // Электронный научный журнал «Нефтегазовое дело». 2010. № 2. URL: http://ogbus.ru/files/ ogbus/authors/BeloborodovaNA/BeloborodovaNA_2.pdf (дата обращения: 04.08.2019).

13. Pennypacker J.S. The Principles of Project Management. New York: PMI, 1997. 232 p.

14. Turner J.R. The Handbook of Project-Based Management. London: McGraw-Hill Companies, 1999. 414 p.

15. Курамшина А.В. Система управления затратами промышленного предприятия // Электронный научный журнал «Нефтегазовое дело». 2006. № 2. URL: http://ogbus.ru/files/ogbus/authors/Kuramshina/Kuramshina_1.pdf (дата обращения: 04.08.2019).

16. Кузнецова Е.В., Гельман А.А. Инновационные подходы к снижению совокупных затрат на инфраструктурные объекты предприятий топливно-энергетического комплекса // Инновации в управлении региональным и отраслевым развитием: матер. Всеросс. научн.-практ. конфер. с междунар. участием. Тюмень: Тюменский индустриальный университет, 2017. С. 97-100.

17. Хакимова К.Р., Котов Д.В. Совершенствование управления инновациями как условие роста производительности труда // Электронный научный журнал «Нефтегазовое дело». 2016. № 5. С. 164-181. URL: http://ogbus.ru/files/ogbus/issues/5_2016/ogbus_5_2016_p164181_KhakimovaKR_ru.pdf (дата обращения: 04.08.2019).

18. Bubshait K.A., Selen W.J. Project Characteristics that Influence the Implementation of Project Management Techniques: a Survey // International Journal of Project Management. 1992. Vol. 23. No. 2. P. 43-47.

19. Thambhain H.J. Best Practices for Controlling Technology-Based Projects According to Plan // PMI Symposium. New Orleans, USA, 1995. P. 550-559. 
20. Прокопьев А.П., Иванчура В.И., Емельянов Р.Т., Пальчиков П.А. Реализация концепции автоматизации и интеллектуализации управления дорожно-строительными процессами//Вестник МГСУ. 2018. Т. 13. № 1 (112). C. 61-70.

URL: https://elibrary.ru/download/ elibrary_32358166_85853402.pdf._(дата обращения: 04.08.2019).

21. Алферов В.И. Модели и методы распределения ресурсов при управлении проектами дорожного строительства: дис. ... д-ра техн. наук. Воронеж: Воронежский государственный архитектурно-строительный университет, 2011.287 с.

22. Алферов В.И., Баркалов С.А., Юшин Г.Д. Разработка графиков движения бригад по объектам строительства // Вестник Воронежского государственного технического университета. 2009. Т. 5. № 1. С. 30-34.

23. Гайфуллина М.М., Низамова Г.З. Анализ современного состояния и направления повышения эффективности использования основных фондов в строительной сфере Российской Федерации // Сетевое издание «Нефтегазовое дело». 2018. № 1. С. 162-183. URL: http://ogbus.ru/files/ogbus/issues/1_2018/ogbus_1_2018_p162-

183_GayfullinaMM_ru.pdf (дата обращения: 04.08.2019).

24. Бунькина И.А. Управление качеством в дорожном строительстве // Научное обозрение. 2015. № 18. С. 372-376.

\section{References}

1. Vasileva Yu.P., Khisamutdinov I.A. Ekonomicheskii rost: effektivnost' i resursnaya obespechennost' [Economic Growth: Efficiency and Reserves]. Elektronnyi nauchnyi zhurnal «Neftegazovoe delo» - Electronic Scientific Journal «Oil and Gas Business», 2014, No. 3, pp. 342-358. URL: http://ogbus.ru/files/ogbus/issues/3_2014/ogbus_3_2014_p342358_VasilevaJP_ru.pdf (accessed 04.08.2019). [in Russian]. 
2. Prokop'ev A.P., Ivanchura V.I., Emel'yanov R.T., Pal'chikov P.A. Realizatsiya kontseptsii avtomatizatsii i intellektualizatsii upravleniya dorozhnostroitel'nymi protsessami [Implementation of the Concept of Automation and Intellectualization of Management of Road Construction Processes]. Vestnik MGSU - Vestnik MGSU, 2018, Vol. 13, No. 1 (112), pp. 61-70. DOI: 10.22227/1997-0935.2018.1.61-70. [in Russian].

3. Schtzbach A.M. The Crack and Seat Method of Pavement Rehabilitation. Public Works, 1989, No. 12, pp. 52-55.

4. Le joint actif. Revue Generale des Routes et des Aerodromes, 1990, No. 677, pp. 49-51.

5. Prokop'ev A.P., Ivanchura V.I., Klimov A.S., Emel'yanov R.T. Kontseptsiya kompleksnoi avtomatizatsii upravleniya protsessami stroitel'stva asfal'tobetonnykh dorozhnykh pokrytii [The Concept of Complex Automation of Asphalt Concrete Pavements Construction Process Control]. Stroitel'nye $i$ dorozhnye mashiny - Construction and Road Building Machinery, 2012, No. 8, pp. 36-42. [in Russian].

6. Kuznetsova E.V., Shaimardanova A.A., Bolgova A.S. Kontseptual'nye osnovy inzhiniringa kachestva [Conceptual Foundations of Quality Engineering]. Materialy IV Vserossiiskoi zaochnoi nauchno-prakticheskoi internet-konferentsii «Sovremennye tendentsii $v$ ekonomike $i$ finansakh» [Materials of the IV All-Russian Correspondence Scientific and Practical Internet Conference «Modern Trends in Economics and Finance»]. Ufa, UGNTU Publ., 2014, pp. 109-111. [in Russian].

7. Kolbasin A.M. Algoritm formirovaniya metodologii upravleniya kachestvom innovatsionnykh proektov $\mathrm{v}$ sfere dorozhnogo stroitel'stva [Algorithm for Forming the Methodology of Quality Management Innovative Projects in the Field of Road Construction]. Transportnoe delo Rossii Transport Business of Russia, 2009, No. 12S, pp. 73-74. [in Russian]. 
8. Bokovikova T.N., Shperber D.R., Shperber E.R., Volkova S.S. Application of Oil-Slimes in Road Base and Surface Construction. Elektronnyi nauchnyi zhurnal «Neftegazovoe delo» - Electronic Scientific Journal «Oil and Gas Business», 2011, No. 2, pp. 316-320. URL: http://ogbus.ru/files/ogbus/eng/authors/ Bokovikova/Bokovikova_1e.pdf (accessed 04.08.2019). [in Russian].

9. Alferov V.I., Barkalov S.A., Kurochka P.N. Upravlenie proektami v dorozhnom stroitel'stve [Project Management in Road Construction]. Voronezh, Voronezhskii gosudarstvennyi arkhitekturno-stroitel'nyi universitet Publ., 2009. 432 p. [in Russian].

10. Barkalov S.A. Teoriya $i$ praktika kalendarnogo planirovaniya $v$ stroitel'stve [Theory and Practice of Scheduling in Construction]. Voronezh, VGASA Publ., 1999. 216 p. [in Russian].

11. Maslova O.P., Savkin S.O. Tseli i zadachi investitsionnoi deyatel'nosti predpriyatii neftegazovoi otrasli [The Objectives and Goals in Investment Activities of Operating Companies for the Oil and Gas Industry]. Elektronnyi nauchnyi zhurnal «Neftegazovoe delo» - Electronic Scientific Journal «Oil and Gas Business», 2017, No. 5, pp. 227-250. URL: http://ogbus.ru/files/ogbus/issues/5_2017/ogbus_5_2017_p227250_MaslovaOP_ru_en.pdf (accessed 04.08.2019). [in Russian].

12. Beloborodova N.A. Sovershenstvovanie upravleniya razvitiem goroda $\mathrm{v}$ neftegazovom regione Rossii [Improvement of City Development Management in the Oil and Gas Region of Russia]. Elektronnyi nauchnyi zhurnal «Neftegazovoe delo» - Electronic Scientific Journal «Oil and Gas Business», 2010, No. 2. URL: http://ogbus.ru/files/ogbus/authors/BeloborodovaNA/ BeloborodovaNA_2.pdf (accessed 04.08.2019). [in Russian].

13. Pennypacker J.S. The Principles of Project Management. New York, PMI, 1997. 232 p.

14. Turner J.R. The Handbook of Project-Based Management. London, McGraw-Hill Companies, 1999. 414 p. 
15. Kuramshina A.V. Sistema upravleniya zatratami promyshlennogo predpriyatiya [Industrial Enterprise Cost Management System]. Elektronnyi nauchnyi zhurnal «Neftegazovoe delo» - Electronic Scientific Journal «Oil and Gas Business», 2006, No. 2. URL: http://ogbus.ru/files/ogbus/authors/ Kuramshina/Kuramshina_1.pdf (accessed 04.08.2019). [in Russian].

16. Kuznetsova E.V., Gel'man A.A. Innovatsionnye podkhody k snizheniyu sovokupnykh zatrat na infrastrukturnye ob"ekty predpriyatii toplivnoenergeticheskogo kompleksa [Innovative Approaches to Reducing the Total Cost of Infrastructure Facilities of the Enterprise the Fuel and Energy Complex]. Materialy Vserossiiskoi c mezhdunarodnym uchastiem nauchno-prakticheskoi konferentsii «Innovatsii v upravlenii regional'nym $i$ otraslevym razvitiem» [Materials of the all-Russian Scientific and Practical Conference with International Participation «Innovations in the Management of Regional and Sectoral Development»]. Tyumen, Tyumenskii industrial'nyi universitet Publ., 2017, pp. 97-100. [in Russian].

17. Khakimova K.R., Kotov D.V. Sovershenstvovanie upravleniya innovatsiyami kak uslovie rosta proizvoditel'nosti truda [Innovation Management Development as Requirement of Labour Productivity Growth]. Elektronnyi nauchnyi zhurnal «Neftegazovoe delo» - Electronic Scientific Journal «Oil and Gas Business», 2016, No. 5, pp. 164-181. URL: http://ogbus.ru/files/ ogbus/issues/5_2016/ogbus_5_2016_p164181_KhakimovaKR_ru.pdf (accessed 04.08.2019). [in Russian].

18. Bubshait K.A., Selen W.J Project Characteristics that Influence the Implementation of Project Management Techniques: a Survey. International Journal of Project Management, 1992, Vol. 23, No. 2, pp. 43-47.

19. Thambhain H.J. Best Practices for Controlling Technology-Based Projects According to Plan. PMI Symposium. New Orleans, USA, 1995, pp. 550-559. 
20. Prokop'yev A.P., Ivanchura V.I., Yemel'yanov R.T., Pal'chikov P.A. Realizatsiya kontseptsii avtomatizatsii $i$ intellektualizatsii upravleniya dorozhno-stroitel'nymi protsessami [Implementation of the Concept of Automation and Intellectualization of the Management of Road-Building Processes]. Vestnik $M G S U$ - Bulletin of MGSU, 2018, Vol. 13, No.1 (112), pp. 61-70. [in Russian]. URL: https://elibrary.ru/download/elibrary_32358166_85853402.pdf_(accessed: 04.08.2019).

21. Alferov V.I. Modeli i metody raspredeleniya resursov pri upravlenii proektami dorozhnogo stroitel'stva: dis. ... d-ra tekhn. nauk [Models and Methods of Resource Allocation in Road Construction Project Management: Doc. Engin. Sci. Diss.]. Voronezh, Voronezhskii gosudarstvennyi arkhitekturnostroitel'nyi universitet Publ., 2011. 287 p. [in Russian].

22. Alferov V.I., Barkalov S.A., Yushin G.D. Razrabotka grafikov dvizheniya brigad po ob"ektam stroitel'stva [Development of Train Diagrams of Brigades on Objects of Construction]. Vestnik Voronezhskogo gosudarstvennogo tekhnicheskogo universiteta - Bulletin of Voronezh State Technical University, 2009, Vol. 5, No. 1, pp. 30-34. [in Russian].

23. Gaifullina M.M., Nizamova G.Z. Analiz sovremennogo sostoyaniya i napravleniya povysheniya effektivnosti ispol'zovaniya osnovnykh fondov $\mathrm{v}$ stroitel'noi sfere Rossiiskoi Federatsii [Analysis of the Current State and the Efficiency Increase Direction from Fixed Assets Usage in Construction Sphere of Russian Federation]. Setevoe izdanie «Neftegazovoe delo» - Online Edition «Oil and Gas Business», 2018, No. 1, pp. 162-183. URL: http://ogbus.ru/files/ogbus/issues/1_2018/ogbus_1_2018_p162183_GayfullinaMM_ru.pdf (accessed 04.08.2019). [in Russian].

24. Bunkina I.A. Upravlenie kachestvom v dorozhnom stroitel'stve [Quality Management in Road Construction]. Nauchnoe obozrenie - Science Review, 2015, No. 18, pp. 372-376. [in Russian]. 


\section{Сведения об авторах}

\section{About the authors}

Кузнецова Елена Викторовна, канд. техн. наук, доцент кафедры «Экономика и управление на предприятии нефтяной и газовой промышленности», УГНТУ, г. Уфа, Российская Федерация

Elena V. Kuznetsova, Candidate of Engineering Sciences, Assistant Professor of Enterprise Economics and Management in the Oil and Gas Industry Department, USPTU, Ufa, Russian Federation

e-mail:nsp-rb@mail.ru

Смородова Ольга Викторовна, канд. техн. наук, доцент кафедры «Промышленная теплоэнергетика», УГНТУ, г. Уфа, Российская Федерация

Olga V. Smorodova, Candidate of Engineering Sciences, Associate Professor of Industrial Heat and Power Engineering Department, USPTU, Ufa, Russian Federation

e-mail: olga_smorodova@mail.ru

Кабиров Максуд Курбонхужаевич, студент кафедры «Автомобильные дороги и технология строительного производства», ФГБОУ ВО «УГНТУ», г. Уфа, Российская Федерация

Maksud K. Kabirov, Student of Highways and Structural Engineering Department, USPTU, Ufa, Russian Federation

Алмакаев Руслан Робертович, студент кафедры «Вычислительная техника и инженерная кибернетика», УГНТУ, г. Уфа, Российская Федерация

Ruslan R. Almakaev, Student of Computer Engineering and Cybernetics Department, USPTU, Ufa, Russian Federation 